Check for updates

Cite this: RSC Adv., 2022, 12, 5085

\title{
Surface modification and characterization of waste derived carbon particles to reinforce photo-cured shape memory composites $\uparrow$
}

\author{
Muhammad Atif, (D) *a Muhammad Naeem, ${ }^{\text {a }}$ Ramzan Abdul Karim, ${ }^{b}$ Faiza Ameen ${ }^{c}$ \\ and Muhammad Waseem Mumtaaz ${ }^{\mathrm{d}}$
}

Carbon fillers have been a source of inspiration to accommodate a range of surface chemistries for different applications. In this study different surface chemistries have been compared for shape memory effect on polymeric composites. Sugar industry waste (fly ash) has been utilized to prepare carbon particles named FCB. Surface modification of FCB has been done in two steps, oxidation and thiolation, respectively. In the first step, different reagents have been used to anchor the surface of FCB with oxygenated functionalities. In the second step, oxygenated FCB has been treated with a thiolating agent to covalently link thio groups on its surface. Polymeric composites have been photo cured with both types of particles, separately. A thermal actuation study has been carried out to check the shape recovery behavior of the composites. A quick shape recovery has been observed for thiolated FCB composites, due to thio linkages in the polymeric network. Samples have been characterized by scanning electron microscopy (SEM), attenuated total reflectance (ATR), dynamic light scattering (DLS), thermal gravimetric analysis (TGA), $\mathrm{pH}$, conductivity, acid content particle dispersion, and composite gel content.

Received 13th November 2021
Accepted 2nd February 2022

DOI: $10.1039 / \mathrm{d} 1 \mathrm{ra0} 331 \mathrm{~g}$

rsc.li/rsc-advances
Both of these methods produce irregularity in epoxy composites to enhance shape memory properties.

One of the reported designed materials in epoxy for SMMs is carbon reinforcement. ${ }^{15}$ Surface chemistry of carbon particles, modified with different modifiers, affect their interactions with epoxy monomer ${ }^{16}$ as well as augment the mechanical properties, ${ }^{17}$ elastic and fracture toughness, thermal ${ }^{18}$ and electrical conductivities. ${ }^{19}$ Functionalization of carbon materials has been reported for reduced shape recovery time in epoxy composites relating to type of functionality introduced. ${ }^{\mathbf{2 0 - 2 2}}$

The main focus of this research is to incorporate waste derived carbon particles into epoxy matrix for synthesis of SMMs. Moreover, carbon based epoxy composites are usually cured through heat, ${ }^{20}$ which is a source of pollution. But this research work has prepared functionalized carbon-epoxy composites through a unique eco-friendly photochemical approach. ${ }^{23}$ This photo-curing approach not only has minimized pollution risks but also has distinctive nature in energy saving ${ }^{24}$ and reduced curing time of composites. ${ }^{25}$ Composites prepared through this approach has been observed with high curing conversion and increased thermo-mechanical properties. $^{23}$

\section{Materials}

Fly ash (sugar industry waste) has been used to obtain filler particles (FCB). Potassium dichromate (BDH laboratory), hydrochloric acid (37\% Sigma), bismithtrichloride (Sigma), 


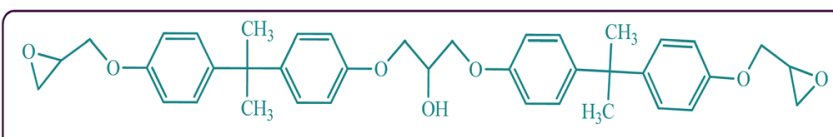

(a)

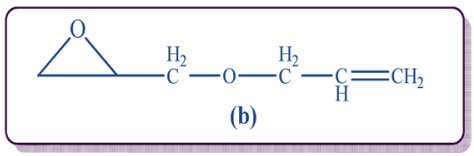

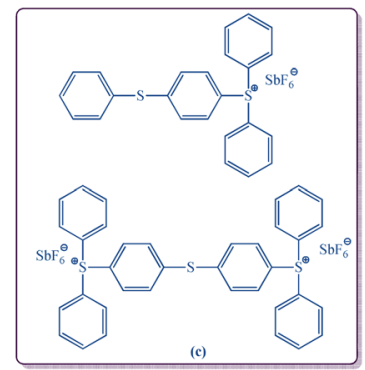

Fig. 1 Epoxies: DGEBA (a), AGE (b); PI (c).

hydrogen peroxide (35\% solution), phenyl hydrazinium (Sigma), chloroaceticacid (Sigma), potassium chlorate (Sigma), sodium azide (Sigma), sulfur (Sigma) and thio-urea (Sigma) have been utilized as surface modifiers. Diglycidyl ether bisphenol A (DGEBA, Sigma), allyl glycidyl ether (AGE, $\geq 99 \%$, Sigma) have been utilized as monomers (Fig. 1a and b). Triarylsulphoniumhexaflouroantimonate salt (50 wt\% propylene carbonate, Sigma) has been used as photo-initiator (PI) see Fig. 1c.

\section{Methods}

FCB was prepared by thermal treatment of fly ash mixed with reagents (as per Table $\mathrm{S} 1 \dagger$ ) in nitrogen atmosphere from r.t. to $500{ }^{\circ} \mathrm{C}$ with a ramp rate of $10^{\circ} \mathrm{C} \mathrm{min}^{-1}$. Thiolation of prepared FCB particles (as per Table $\mathrm{S} 2 \mathrm{f}^{\dagger}$ ) was carried out in nitrogen atmosphere from r.t. to $165^{\circ} \mathrm{C}$ with a ramp rate of $10^{\circ} \mathrm{C} \mathrm{min}{ }^{-1}$. The obtained mixture was ground to powder.

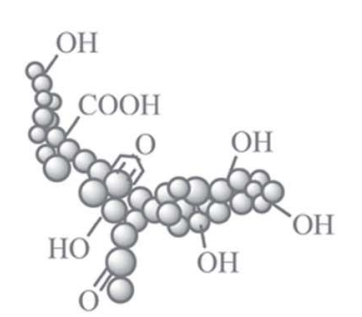

Oxidized,

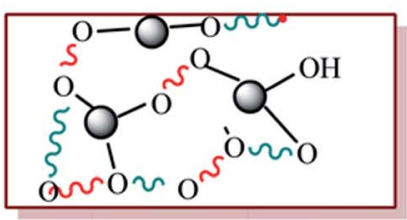

C-FCB Composites

UV
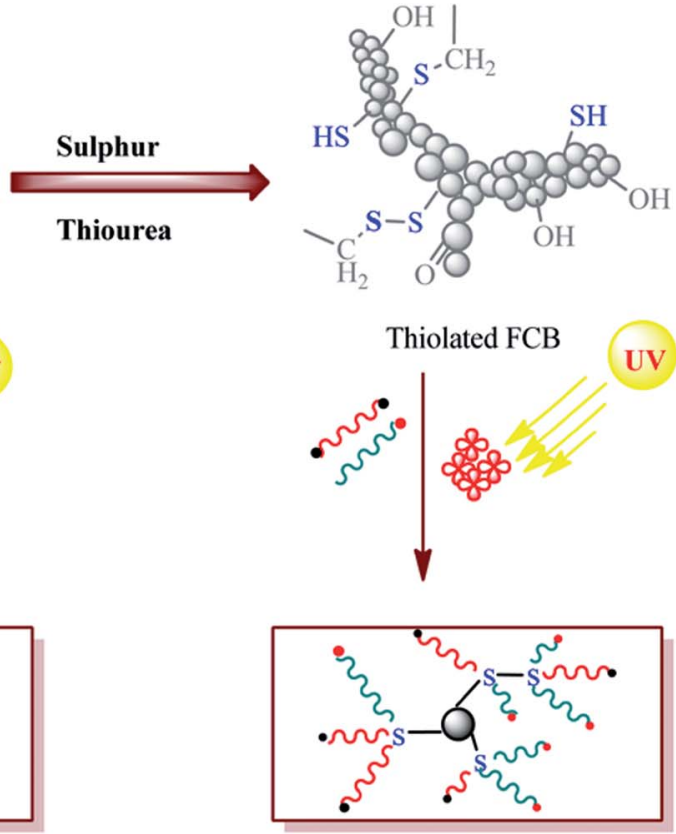

C-FCB-T Composites<smiles>Cc1ccc(OCC(O)COc2ccc(C(C)(C)C)cc2)cc1</smiles>

DGEBA<smiles>C=CCOCC1CO1</smiles>
$=\xi$

Scheme 1 Preparation of filler and composites. 
Table 1 Sample formulation for composite synthesis

\begin{tabular}{llll}
\hline Sample ID & $\begin{array}{l}\text { DGEBA : AGE } \\
\text { (mole ratio) }\end{array}$ & $\begin{array}{l}\text { Filler 1 wt\% } \\
\text { of monomer }\end{array}$ & $\begin{array}{l}\text { PI : monomer } \\
\text { (mole ratio) }\end{array}$ \\
\hline $\begin{array}{l}\text { Pristine epoxy } \\
\text { C-FCB }\end{array}$ & $1: 2$ & Nil & $0.001: 1$ \\
C-FCB1-9 & & FCB & \\
C-FCB-T & & FCB1-9 & \\
C-FCB-T1-T9 & & FCB-TP & \\
& & FCB-T1-T9
\end{tabular}

\subsection{Composites synthesis}

Composite samples were prepared, as per Scheme 1 and Table 1 , through photo curing approach. ${ }^{23}$ Weighed amount of both monomers with $1 \mathrm{wt} \%$ of functionalized filler were mixed by using magnetic stirrer for 25-30 minutes. PI was irradiated, with UV light $(6 \mathrm{~W})$ for one minute and mixed with filler-epoxy mixture.

\subsection{Characterization}

FCB particles were characterized by different instrumental and chemical analyses, including: FTIR/ATR (ALPHA-P Broker) spectra with absorbance range of $4000-500 \mathrm{~cm}^{-1}$; SEM (NTRC; at $20 \mathrm{kV}$ with ETD detector); DLS (Nanosizer, ZS90 Melvern), TGA (SKZ-1060) and acid contents using equation (i) through direct Boehm's titration. ${ }^{26}$

$$
n_{\mathrm{CSf}}=[\mathrm{B}] \times V_{\mathrm{B}}-[\mathrm{HCl}] V_{\mathrm{HCl}} \times V_{\mathrm{B}} / V_{\mathrm{a}}
$$

For zeta potential $(\zeta, \mathrm{ZP})$ analysis $0.005 \mathrm{~g}$ of FCB particles were dispersed in $10 \mathrm{~mL}$ distilled water and ultrasonically mixed for $10 \mathrm{~min}$. $\zeta$ values exposed the charge present at the surface of particles. For conductivity and $\mathrm{pH}$ test $0.1 \mathrm{~g}$ of each sample was dispersed in $10 \mathrm{~mL}$ distilled water, stirred for $30 \mathrm{~min}$ and $\mathrm{pH} /$ conductivity were taken at room temperature.

Composites were characterized by FTIR/ATR (ALPHA-P Broker) spectra with absorbance range of 4000-500 $\mathrm{cm}^{-1}$, SEM (NTRC; at $20 \mathrm{kV}$ with ETD detector); DSC and TGA (SKZ1060), gel contents according to ASTM D2765-84, by using eqn (ii) and (iii)

$$
\% \text { Extract }=\left(W_{\mathrm{s}}-W_{\mathrm{d}}\right) / W_{\mathrm{s}} \times 100
$$

$$
\% \text { Gel content }=100-\% \text { extract }
$$

$W_{\mathrm{s}}=$ weight of specimen being tested, $W_{\mathrm{d}}=$ weight of dried gel.

ATR degree of cure ( $\left.\mathrm{DC}_{\mathrm{ATR}}\right)$ was estimated by formula (iv), where $A_{0}$ and $A_{t}$ denoted uncured and cured epoxy peak area $\left(926 \mathrm{~cm}^{-1}\right)$, respectively.

$$
\% \mathrm{DC}_{\mathrm{ATR}}=\left(A_{0}-A_{t} / A_{0}\right) \times 100
$$

Curing conversion through thermal-DSC (TA Q2000 DSC) was calculated by eqn (v).

$$
\% \mathrm{DC}_{\mathrm{DSC}}=\left(1-H_{\mathrm{DSC}} / H_{\mathrm{Tot}}\right) \times 100
$$

Shape recovery behavior of prepared composites was studied by indirect heating above glass transition temperature $\left(T_{\mathrm{g}}\right)$ i.e. 85-90 ${ }^{\circ} \mathrm{C}$, which generated soft domains in samples, triggering chain mobility. Then samples were cooled and molded into desired temporary shape. Shape recovery time was found by placing deformed samples in pre-heated glass chamber. This heating released the stored elastic energy and recovery of original shape was observed by using eqn (vi)

$$
\% \mathrm{SR}=l_{\mathrm{R}} / l_{\mathrm{D}} \times 100
$$

$\% \mathrm{SR}=$ percentage shape recovery; $l_{\mathrm{D}}=$ length of total deformed shape; $l_{\mathrm{R}}=$ length of recovered shape.

\section{Results and discussion}

FCB particles have been prepared by thermal treatment of sugar industry waste. Different oxygen containing moieties (hydroxyl, carboxylic acid, phenolic and lactic acid) were introduced onto the surface of particles through different modifiers. The second phase of modification was carried out to introduce thio offshoots on oxidized FCB particles. Both oxidized and thiolated particles were used as filler in epoxy matrix to prepare shape memory composites.

FTIR/ATR absorbance analysis (500-4000 $\left.\mathrm{cm}^{-1}\right)$ showed that after treatment FCB-1, 5 and 6 (Fig. 2a) have peaks at around $3300 \mathrm{~cm}^{-1}$ verifying hydroxyl group generation. Characteristic peak at $1600 \mathrm{~cm}^{-1}$ in all samples suggest presence of carbonyl group. ${ }^{27} \mathrm{~A}$ further confirmation of these functionalities has a)

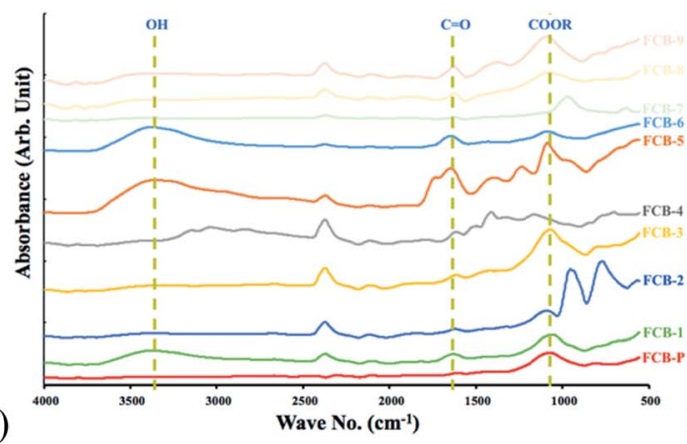

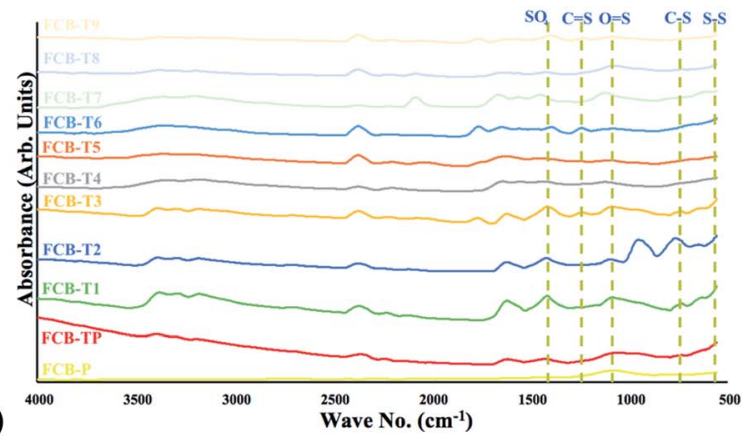

Fig. 2 ATR analysis of (a) oxidized, (b) thiolated FCB particles. 
a)

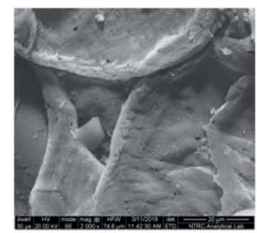

f)

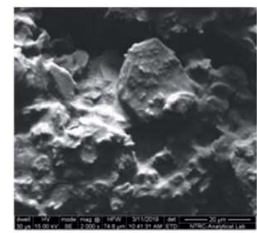

k)

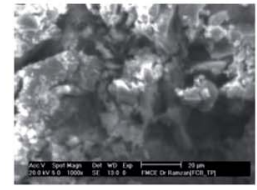

p)

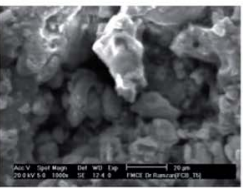

b)

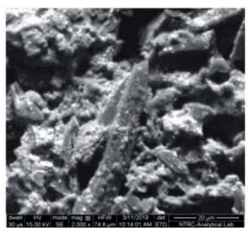

g)

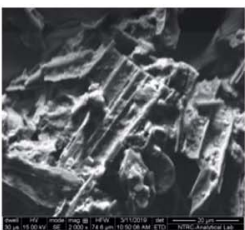

1)

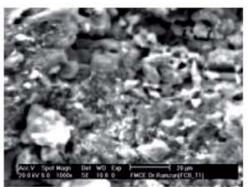

q)

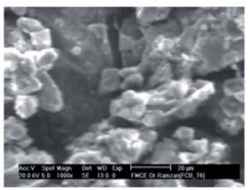

c)

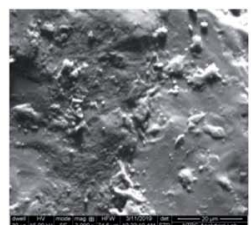

h)

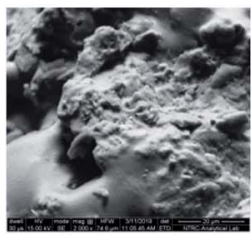

m)

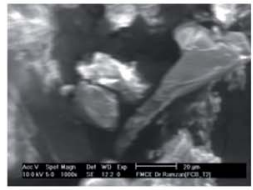

r)

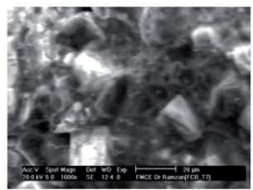

d)

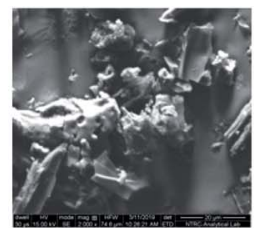

i)

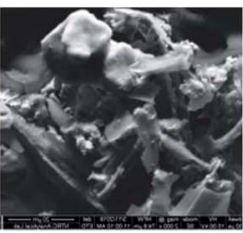

n)

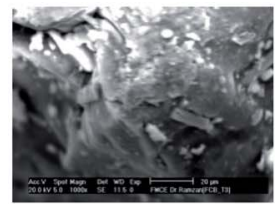

s)

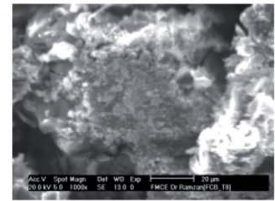

e)

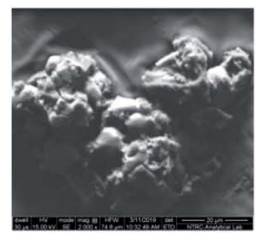

j)

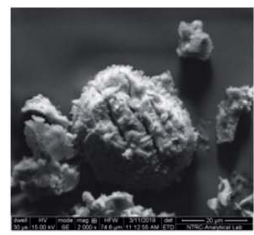

o)

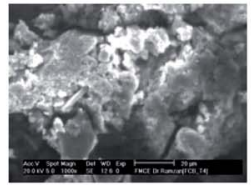

t)

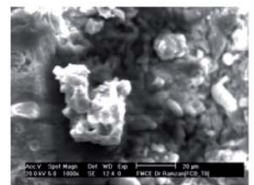

Fig. 3 SEM images of oxidized (a) FCB, (b-j) FCB 1-9, (k) FCB-TP, (l-t) FCB T1-T9.

been done through Bohem titration (Table 3). In thiolated particles (Fig. 2b) prominent peaks in FCB-T1, T2, T3 and T6 at $560 \mathrm{~cm}^{-1}$ (S-S), $640 \mathrm{~cm}^{-1}(\mathrm{C}-\mathrm{S}), 1030 \mathrm{~cm}^{-1}(\mathrm{~S}=\mathrm{O}), 1250 \mathrm{~cm}^{-1}$ $(\mathrm{C}=\mathrm{S})$ and $1340 \mathrm{~cm}^{-1}$ (sulfate/sulfones) confirmed effectiveness of thiolation treatment. ${ }^{27,28}$ Sulfur functionalities particularly disulfide and sulfones have been reported for shape memory response. ${ }^{29} \mathrm{~A}$ distinctive peak has been observed at $914 \mathrm{~cm}^{-1}$ in two samples i.e. FCB-2 and FCB-7, treated with potassium dichromate and potassium chlorate. Both of these modifiers have been reported for oxirane manufacturing. ${ }^{30,31}$

TGA $\left(25-800{ }^{\circ} \mathrm{C}\right)$ of oxidized FCB showed better thermal stability than thiolated FCB (Fig. S1a and $\mathrm{b} \dagger$ ). This might be attributed to the fact that during preparation, oxidized FCB particles developed compact agglomerated structures whereas thiolated particles grew amorphous morphologies. All oxidized FCB particles showed $20 \%$ weight loss at $800{ }^{\circ} \mathrm{C}$, except FCB-5 which showed $40 \%$ weight loss. In contrast to that all thiolated particles started decomposing at $300{ }^{\circ} \mathrm{C}$ and showed $60-$ $80 \%$ weight loss at $800{ }^{\circ} \mathrm{C}$, except FCB-T1 which showed maximum weight loss at $340{ }^{\circ} \mathrm{C}$ and FCB-T2 which showed minimum weight loss at $800{ }^{\circ} \mathrm{C}$ (Fig. S1b $\dagger$ ). These findings indicate that thiolated samples have better thermal dissipation behavior, which proved to be a strength in thermally actuated shape memory behavior.

SEM analysis of oxidized and thiolated samples (Fig. 3) has been recorded to observe morphological changes in FCB structure. FCB has quite a smooth surface, but after modification all samples (Fig. $3 \mathrm{~b}-\mathrm{j}$ ) presented rough surfaces. Harsh oxidative treatment has transformed larger smooth particles into smaller itched surface structures. No doubt, particle size is an essential component for its dispersive behavior in solvent or media, yet, surface chemistry is inevitably vital in this context. FCB-4 (Fig. 3e) has shown excellent dispersion in commonly used solvents i.e. acetone, ethyl acetate and dichloromethane. The sample has acidic $\mathrm{pH}$ (4.2), higher conductivity (23.265 $\left.\mathrm{mS} \mathrm{cm}^{-1}\right)$ and ZP $(-20.1 \mathrm{mV})$ than FCB, indicating effective surface modification for long lasting dispersion.

Table 2 Zeta potential, $\mathrm{pH}$ and conductivity of oxidized and thiolated FCB particles

\begin{tabular}{lclll}
\hline & & \multicolumn{2}{l}{$\mho\left(\mathrm{mS} \mathrm{cm}^{-1}\right)$} & \\
\cline { 3 - 4 } Sample ID & $\zeta(\mathrm{mV})$ & Melvern zeta & Conductometer & $\mathrm{pH}$ \\
\hline & & & & \\
FCB & -02.5 & 0.101 & 00.865 & 9.9 \\
FCB-1 & -22.0 & 1.090 & 27.700 & 7.8 \\
FCB-2 & -18.4 & 0.640 & 56.052 & 7.3 \\
FCB-3 & -22.7 & 0.245 & 01.775 & 3.4 \\
FCB-4 & -20.1 & 0.664 & 23.265 & 4.2 \\
FCB-5 & 3.36 & 0.661 & 06.283 & 4.8 \\
FCB-6 & 39.0 & 0.402 & 06.152 & 5.0 \\
FCB-7 & -36.2 & 0.911 & 23.578 & 8.5 \\
FCB-8 & -30.9 & 0.422 & 07.180 & 6.8 \\
FCB-9 & -19.2 & 0.277 & 06.142 & 6.7 \\
FCB-TP & 03.7 & 0.007 & 00.754 & 9.9 \\
FCB-T1 & 13.9 & 0.823 & 17.092 & 8.3 \\
FCB-T2 & 02.7 & 0.420 & 09.953 & 7.5 \\
FCB-T3 & 10.4 & 0.0731 & 00.610 & 8.2 \\
FCB-T4 & 22.4 & 0.134 & 09.247 & 4.8 \\
FCB-T5 & -18.5 & 0.037 & 03.765 & 5.6 \\
FCB-T6 & -21.5 & 0.252 & 02.559 & 6.3 \\
FCB-T7 & 25.7 & 0.044 & 27.592 & 6.7 \\
FCB-T8 & -10.7 & 0.057 & 02.170 & 6.2 \\
FCB-T9 & -16.3 & 0.050 & 01.537 & 6.1
\end{tabular}


Table 3 Acid contents of unmodified and modified particles

\begin{tabular}{|c|c|c|c|c|}
\hline Sample ID & $\begin{array}{l}\text { Carboxylic content } \\
\left(\mu \mathrm{mol} \mathrm{g}^{-1}\right)\end{array}$ & $\begin{array}{l}\text { Lactonic content } \\
\left(\mu \mathrm{mol} \mathrm{g}{ }^{-1}\right)\end{array}$ & $\begin{array}{l}\text { Phenolic content } \\
\left(\mu \mathrm{mol} \mathrm{g}{ }^{-1}\right)\end{array}$ & $\begin{array}{l}\text { Total acid content } \\
\left(\mu \mathrm{mol} \mathrm{g}{ }^{-1}\right)\end{array}$ \\
\hline FCB & 0.01 & 0.04 & 0.54 & 0.59 \\
\hline FCB-2 & 0.35 & 0.3 & 1.425 & 2.075 \\
\hline FCB-3 & 0.25 & 0.125 & 1.525 & 1.9 \\
\hline FCB-4 & 0.25 & 0.125 & 1.675 & 2.05 \\
\hline FCB-7 & 0.15 & 0.1 & 1.5 & 1.75 \\
\hline FCB-8 & 0.266 & 0.084 & 1.575 & 1.925 \\
\hline FCB-9 & 0.275 & 0.075 & 1.625 & 1.975 \\
\hline FCB-TP & 00 & 0.44 & 0.44 & 0.88 \\
\hline FCB-T-1 & 00 & 0.28 & 0.6 & 0.88 \\
\hline FCB-T-2 & 00 & 0.55 & 0.43 & 0.98 \\
\hline FCB-T-7 & 00 & 0.28 & 0.67 & 0.95 \\
\hline FCB-T-8 & 00 & 0.37 & 0.65 & 1.02 \\
\hline FCB-T-9 & 00 & 0.4 & 0.44 & 0.84 \\
\hline
\end{tabular}

Upon thiolation, a visible change observed is shiny white coating on particles, although slight morphological alterations have also been observed (Fig. $3 \mathrm{k}-\mathrm{t}$ ). The surface coated with thio moieties have also been confirmed by FTIR analysis. Surface covered with $\mathrm{S}-\mathrm{S}, \mathrm{S}=\mathrm{O}$ and $\mathrm{C}=\mathrm{S}$ have a major role in shape memory designing, by developing soft region of polymeric assembly.

A range of $\mathrm{ZP}$ for prepared samples indicates qualitative and quantitative diversity of charges present on particles' surfaces (Table 2). Oxidative treatment of unmodified FCB enhanced ZP values, then thiolation comparatively decreased $\mathrm{ZP}$ of samples. An augmentation of $\mathrm{ZP}$ at the first modification step signposts incorporation of charged bodies on FCB surface, then decline in $\mathrm{ZP}$ in the second modification step indicates substitution of charges with other functionalities. Moreover, in both treatments a reduction in $\mathrm{pH}$ of samples has been observed. Oxidation process dropped high $\mathrm{pH}$, causing samples to be more acidic, consequently strengthening cationic curing of epoxy through activated monomer (AM) mechanism. However, on the other side, hydrogen bonding probability increased causing a delay in shape recovery of oxidized FCB composites.

A diverse range in surface chemistry of carbon particles (carboxyl, phenolic, lactonic etc.) helps to control composite properties especially through inter-intra collaborations. An estimation of surface oxy groups of carbon materials has been made through Boehm titration. ${ }^{26,32,33}$ FCB-5, among oxidized FCB particles, has been observed with the highest amount of acidic contents, likewise FCB-T8 has been observed with

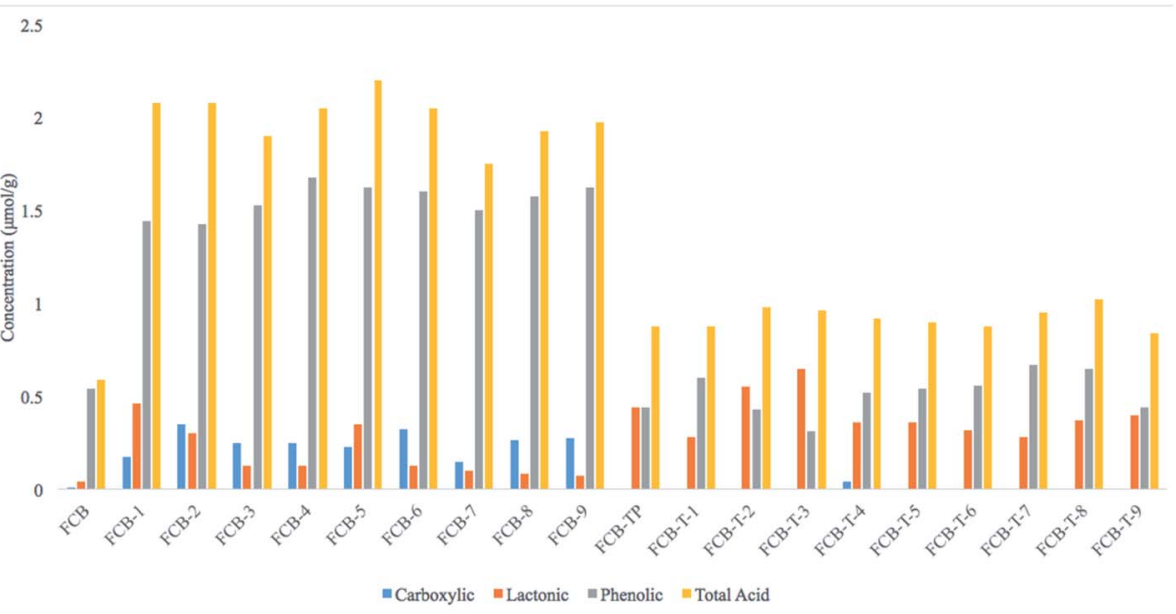

Fig. 4 Acid contents of unmodified and modified particles. 
a)

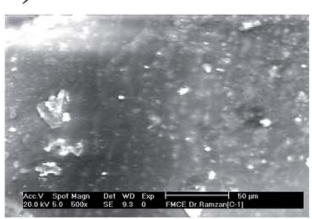

f)

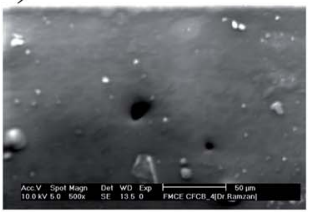

k)

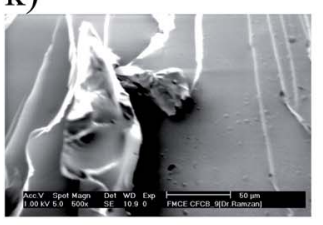

b)

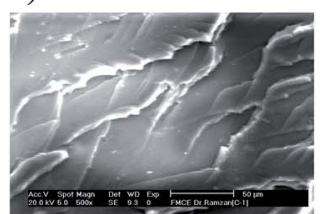

g)

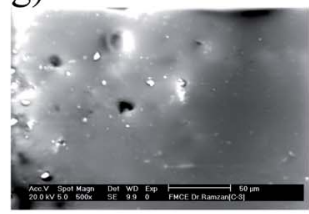

1)

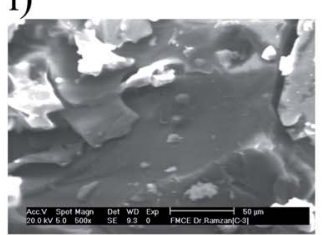

c)

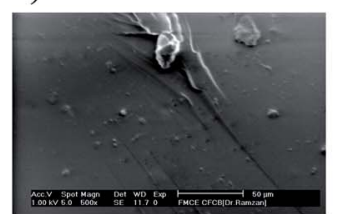

h)

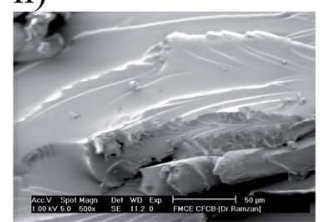

m)

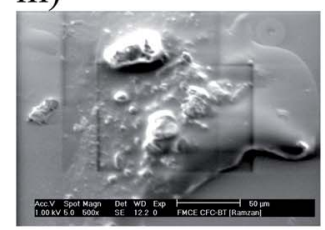

p) d)

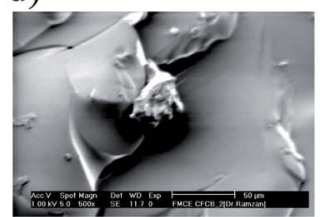

i)

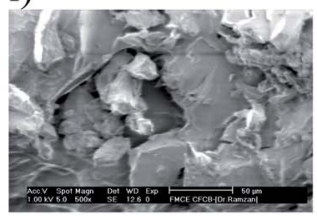

n)

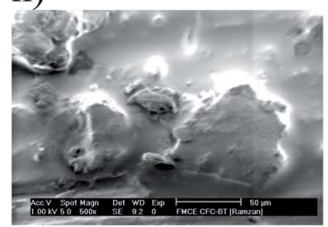

e)

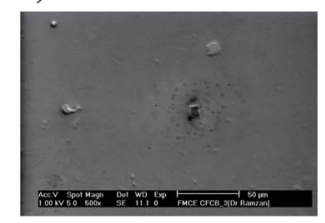

j)

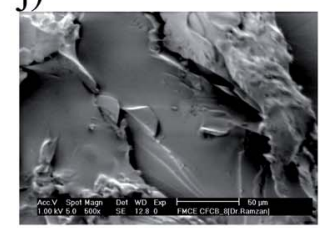

o)

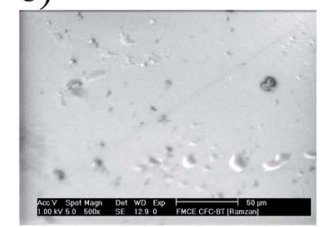

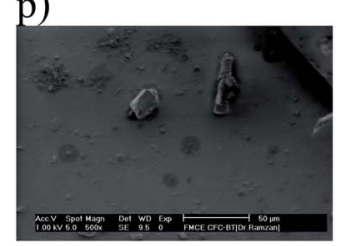

Fig. 5 SEM images of (a) Neat epoxy, (b) CFCB, (c-k) CFCB-1-9, (l) CFCB-TP, (m-o) CFCB-T1-T3, (p) CBCF-T6.

maximum acidic contents in thiolated samples (Table 3 and Fig. 4). Both these samples may have a trend to establish hydrogen bonded crosslinking ultimately producing rigid polymeric structure, with the least shape recovery behavior. Overall oxidized particles have been found with greater acidic contents, which have also been confirmed through FTIR/ATR analysis and $\mathrm{ZP}$ values.

Uniform dispersion of particles in solvent is essential to avoid agglomeration and subsequent improvement in composite properties. Unmodified and modified FCB particles have been dispersed in a range of solvents (acetone, ethyl acetate, dichloromethane and water) to check their dispersion stability (Fig. S2-S5†).

Oxidized particles showed excellent dispersion in water (Fig. S2a $\dagger$ ), whereas only thiolated particle FCB-T1 showed comparable dispersion in water. The reason for oxidized samples could be high concentration of hydroxyl and carbonyl functionalities supporting dispersion, whereas for thiolated sample reason could be higher ratio of ionic bonds, originated from bismuth trichloride.

Dispersion analysis of prepared samples has also been done in a range of solvents, and different responses have been found. In acetone FCB-3, FCB-4 \& FCB-T4 showed good dispersion (Fig. S3a and $b \dagger$ ). In ethyl acetate FCB-4 and FCB-T1 showed excellent dispersion (Fig. S4a and $\mathrm{b} \dagger$ ). In DCM, FCB-3, FCB-4 and FCB-T1 gave better dispersion (Fig. S5a and $\mathrm{b}_{\dagger}^{\dagger}$ ). The observations clearly suggest that a variety in surface chemistry

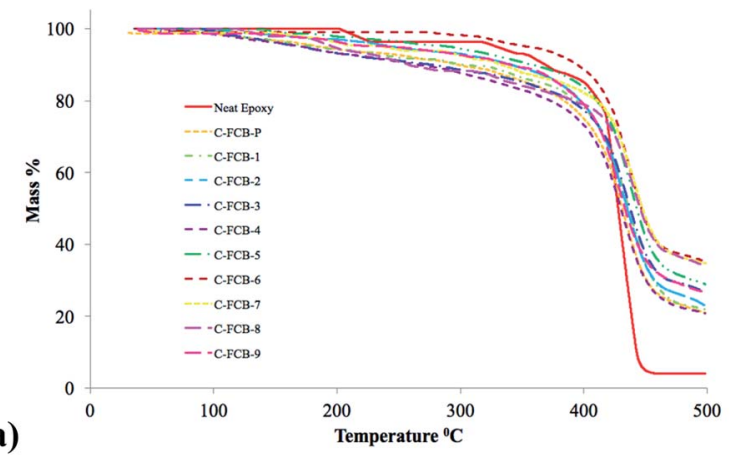

b)

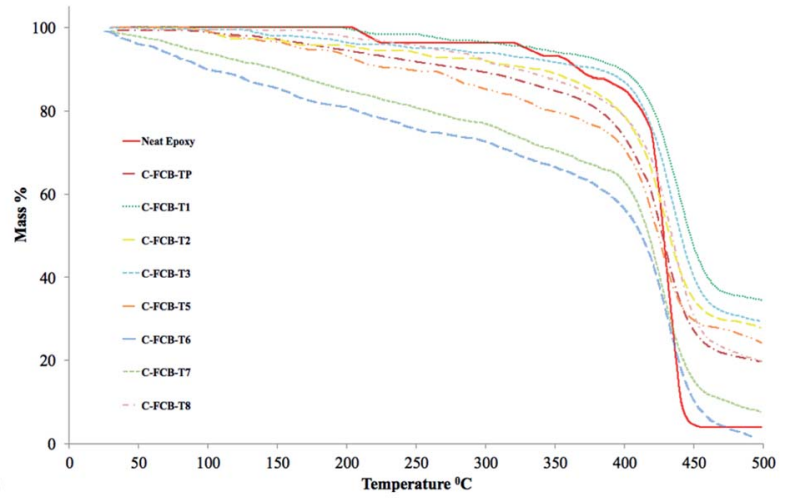

Fig. 6 TGA of (a) neat epoxy, unmodified and oxygenated FCB composites, (b) thiolated FCB composites. 
Table 4 Shape recovery measurements of composites

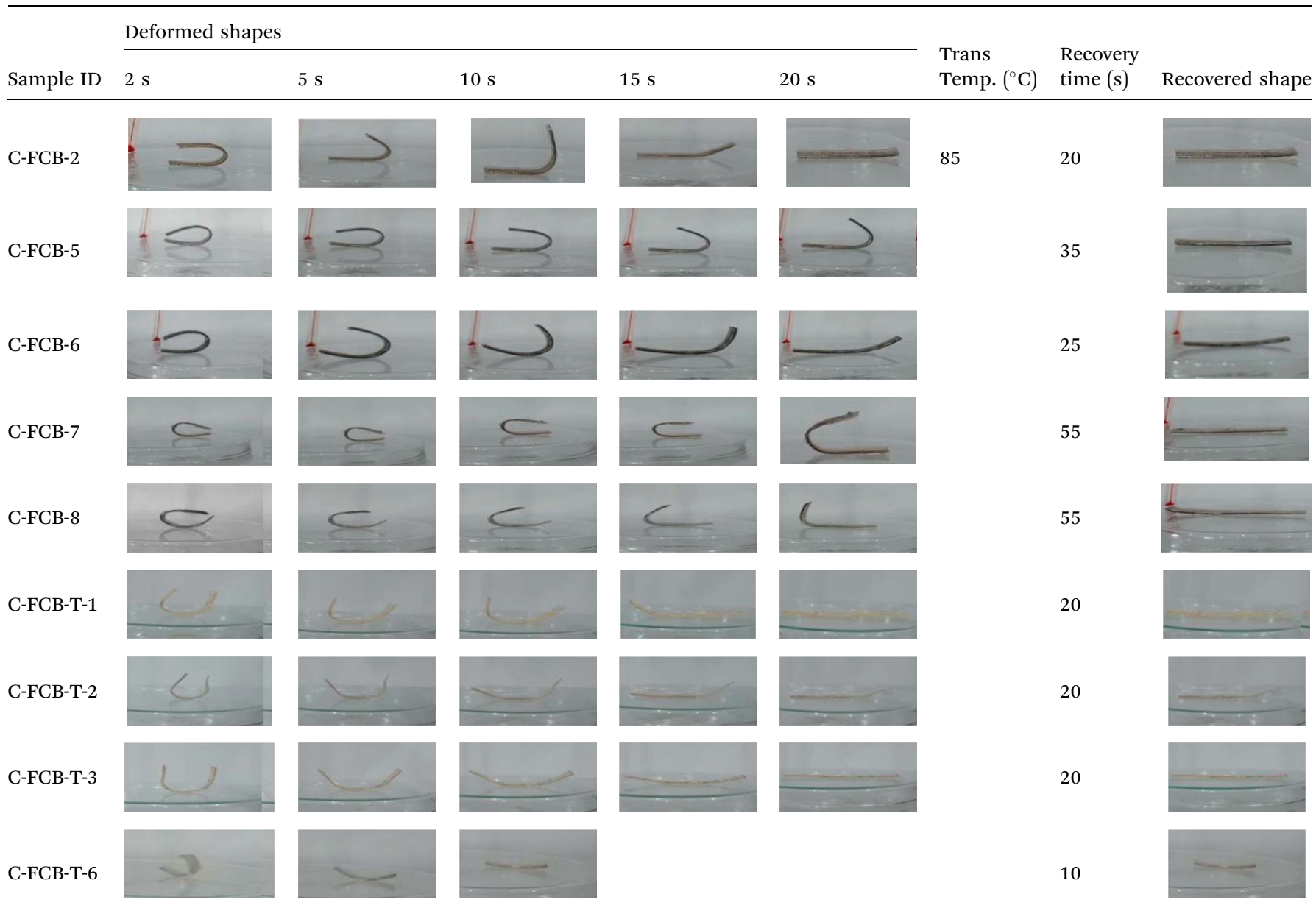

and morphology can support an array of inter-intra connections between particle-media.

After complete analyses and understanding of surface chemistry, prepared oxidized and thiolated particles were incorporated in epoxy matrix to design shape recovery composites. A comparison has been made between pristine epoxy, unmodified FCB composites and modified FCB composites. SEM images (Fig. 5b-p) evidenced dispersion uniformity of filler and matrix in all samples, irrespective of filler surface chemistry. This dispersion evenness might be attributed to UV curing approach, which links a separate phase of active center generation from PI, with sufficient homogenization period for filler and matrix.

Prepared composites were characterized for thermal stability by TGA in temperature range of $25-500{ }^{\circ} \mathrm{C}$ (Fig. 6 and Table S3†). It was observed that neat epoxy showed better thermal stability before $400{ }^{\circ} \mathrm{C}$ and the least thermal stability after $400{ }^{\circ} \mathrm{C}$, which might be attributed to the fact that neat epoxy made a compact and thermally stable polymer till $400{ }^{\circ} \mathrm{C}$ which afterwards started disintegrating. On the contrary, composites showed quick weight loss till $400{ }^{\circ} \mathrm{C}$, which indicates that oxy surface functionalities of fillers helped combustion process and thermal damage to filler (carbon natured) subsequently destroyed polymer. After $400{ }^{\circ} \mathrm{C}$, composite samples got stabilized by heat dissipation behavior of residual filler.

Curing conversion of neat epoxy and composite samples has been determined to verify crosslinking in polymeric network (Table S4 and Fig. S6†). It has been observed that incorporation of filler enhanced curing conversion, representing a strong filler-matrix interaction. Data revealed that composites having functionalized filler particles showed higher conversion than composite with unmodified filler.

Prepared composites have been tested for shape recovery by using indirect heating. Here the epoxy systems containing FCB particles as filler have been subjected to deformation and checked for shape recovery time at $T_{\mathrm{g}}$. Thiolated filler composites showed faster shape recovery than oxidized filler composites (Tables 4, S5 and Fig. S7 $\dagger$ ). The reason of difference in thermally actuated shape recovery response lies in surface functionalities developed during modification protocols. In oxidized composites oxygenated functionalities played dual role, i.e. hydroxyl functionalities not only contributed in epoxy curing through well-known activated monomer mechanism, but also developed hydrogen bonding at the same time. 
Activated monomer mechanism develops $\mathrm{C}-\mathrm{O}-\mathrm{C}$ bond that adds to soft region of polymeric assembly, whereas hydrogen bonding develops linkages that reduce degrees of freedom which results in hard region of polymeric composites. On the contrary, in thiolated composites, thioether, disulfide, carbonyl sulfide and sulfone linkages all take responsibility for constructing soft region of polymer, hence support shape recovery upon thermal actuation. All these linkages are much more elastic than the oxygenated groups and helps in fast shape recovery.

Shape recovery measurements of composites are presented in Fig. S7. $\uparrow$ Neat epoxy was prepared as standard to analyze the trend of shape recovery in matrix, and it was observed to have $63 \mathrm{~s}$ time to recover $100 \%$ of original shape. Out of oxidized samples C-FCB-2 showed minimum time (i.e. $20 \mathrm{~s}$ ) to $100 \%$ shape recovery. The reason behind is elastic connections of FCB-2 with polymeric matrix. FTIR of the said sample showed the least hydroxyl species and a peak at $914 \mathrm{~cm}^{-1}$ confirming oxirane like structure. Both these factors support the fact that FCB-2 (hard region) got incorporated into epoxy matrix through glycidyl linkage (soft region) which provided the support to quick shape recovery. The sample had neutral $\mathrm{pH}$ (7.3) which supports implemented UV curing procedure. FTIR of sample FCB-7 also showed the least hydroxyl content and oxirane peak at $914 \mathrm{~cm}^{-1}$, but the shape recovery time is 2.5 times greater. The reason is justified by sample's basic $\mathrm{pH}$ (8.5) which decelerates implemented UV curing procedure, hence decreases the elastic connections between FCB-7 and epoxy matrix.

Thiolated particles imparted quick shape recovery behavior in composites. Samples C-FCB-T6 showed the least shape recovery time (10 s) in all prepared samples. Particle FCB-T6 was prepared from FCB-6 having acidic $\mathrm{pH}$ and high concentration of hydroxyl and carbonyl group, which anchored sulfur as thioether and carbonyl sulfide. Thioether itself has elasticity, and carbonyl sulfide developed thioether linkage as per proposed Scheme S1. $\dagger$

Electropositive carbon got attacked by oxirane oxygen, then electronegative sulfur attacked another oxirane carbon, to make a link between epoxy monomers, during propagation.

\section{Conclusion}

Modification of filler particles with different modifiers, have resulted in specific surface functionalities, which has been confirmed through chemical and instrumental analyses. Oxidation seeded oxygenated functionalities that contributed hydrogen bonding in different components of composites, whereas thiolation introduced thioether, disulfide, carbonyl sulfide and sulfones onto particles' surface for thiolated bridges between different components of composites. Instrumental analyses have confirmed thiolated FCB with smaller morphology and better thermal dissipation. This added on to the shape recovery phenomenon in thiolated composites. Prepared particles have shown a range of $\mathrm{pH}$ and zeta potential values, labelling their effective dispersion and interaction capability with a range of solvents/media. Curing conversion of composites, determined by gel contents, ATR and DSC, have shown thiolated composites with the highest values in comparison to oxygenated composites and neat matrix. Thiolated composites have shown very quick shape recovery within 10-20 s, whereas oxidized composites have shown it in 20-55 s and neat epoxy in $63 \mathrm{~s}$. Structure activity study has shown the role of thioether surface functionalities in quick shape recovery, making them a promising candidate to be further explored for micro-devices, deployable structures, actuators, biomedical equipment and origami structures.

\section{Data availability}

The raw data has already been provided in the article to reproduce the findings.

\section{Funding}

This study was funded by Higher Education Commission of Pakistan (NRPU 6475).

\section{Conflicts of interest}

The authors declare that they have no conflict of interest.

\section{References}

1 M. Sattari, et al., Wear in superelastic shape memory alloys: A thermomechanical analysis, Wear, 2022, 488, 204139.

2 A. Lendlein, et al., Bioperspectives for shape-memory polymers as shape programmable, active materials, Biomacromolecules, 2019, 20(10), 3627-3640.

3 Z. Du, et al., Superelasticity in micro-scale shape memory ceramic particles, Acta Mater., 2017, 123, 255-263.

4 S. Reddy, Smart materials for 4D printing: a review on developments, challenges and applications, Recent Advances in Manufacturing, Automation, Design and Energy Technologies, 2022, pp. 3-10.

$5 \mathrm{~J}$. Chakraborty, et al., Technology and application of shape memory polymers in textiles, Res. J. Text. Apparel, 2017, 21(2), 86-100.

$6 \mathrm{~N}$. Sabahi, et al., A review on additive manufacturing of shape-memory materials for biomedical applications, JOM, 2020, 72(3), 1229-1253.

7 G. Song, et al., Applications of shape memory alloys in offshore oil and gas industry: a review, in Earth and Space 2010: Engineering, Science, Construction, and Operations in Challenging Environments, 2010, pp. 1551-1567.

8 M. Guida, et al., Analysis of the impact dynamics of shape memory alloy hybrid composites for advanced applications, Materials, 2019, 12(1), 153.

9 N. Ma, et al., Application of shape memory materials in protective clothing: a review, J. Text. Inst., 2018, 110(6), 950-958.

10 Z. Wang, et al., Programmable, pattern-memorizing polymer surface, Adv. Mater., 2011, 23(32), 3669-3673. 
11 X. Lan, et al., Fiber reinforced shape-memory polymer composite and its application in a deployable hinge, Smart Mater. Struct., 2009, 18(2), 024002.

12 W. G. Yang, et al., Advanced shape memory technology to reshape product design, manufacturing and recycling, Polymers, 2014, 6(8), 2287-2308.

13 C. M. Yakacki, et al., Unconstrained recovery characterization of shape-memory polymer networks for cardiovascular applications, Biomaterials, 2007, 28(14), 2255-2263.

14 Q. Zhao, et al., Shape memory polymer network with thermally distinct elasticity and plasticity, Sci. Adv., 2016, 2, e1501297.

15 X. Tan, et al., Effects of Regular Networks Composed of Rigid and Flexible Segments on the Shape Memory Performance of Epoxies, Ind. Eng. Chem. Res., 2018, 57(23), 7898-7904.

16 F. Ameen, et al., Qualitative and quantitative impact of filler on thermomechanical properties of epoxy composites, Polym. Adv. Technol., 2021, 32, 2813-2828.

17 M. Atif, et al., Electrochemical evaluation of textile industry waste derived carbon particles for UV-cured epoxy composites, Diamond Relat. Mater., 2020, 107804.

18 M. Atif, et al., Facile Oxidation Approach to Amend Surface Chemistry of Carbon Particles for Augmented Dispersion in Epoxy Matrix, Russ. J. Appl. Chem., 2020, 93(2), 305-312.

19 M. Atif, et al., Electrochemical Evaluation of Human Hair Derived Carbon Particles, ECS J. Solid State Sci. Technol., 2020, 9(5), 051003.

$20 \mathrm{~J}$. Karger-Kocsis and S. Kéki, Review of progress in shape memory epoxies and their composites, Polymers, 2018, $10(1), 34$.

21 Y. Wang, et al., Preparation of modified multi-walled carbon nanotubes as a reinforcement for epoxy shape-memory polymer composites, Polym. Adv. Technol., 2021, 32(1), 6775.

22 G. Y. Romero-Zúñiga, et al., Enhanced mechanical performance of a DGEBA epoxy resin-based shape memory polymer by introducing graphene oxide via covalent linking, J. Appl. Polym. Sci., 2022, 139(2), 51467.
23 M. Atif, et al., Effect of novel UV-curing approach on thermomechanical properties of colored epoxy composites in outsized dimensions, J. Compos. Mater., 2016, 50(22), 3147-3156.

24 M. Atif, et al., Photochemical thiolation of carbon particles with mercaptoproyltrimethoxy silane, Compos. Interfaces, 2020, 27(6), 617-630.

25 M. Atif, et al., Cationically UV-cured epoxy composites, Polym. Rev., 2015, 55(1), 90-106.

26 I. I. Salame and T. J. Bandosz, Surface chemistry of activated carbons: combining the results of temperature-programmed desorption, Boehm, and potentiometric titrations, J. Colloid Interface Sci., 2001, 240(1), 252-258.

27 M. F. Rahman, J. Hossain, A. Kuddus, M. M. A. Moon and A. B. M. Ismail, Effect of Triton X-100 surfactant on thiolamine cosolvents assisted facile synthesized CdS thin films on glass substrate by spin coating method, SN Appl. Sci., 2020, 2(4), 1-12.

28 B. S. Chiou and S. A. Khan, Real-time FTIR and in situ rheological studies on the UV curing kinetics of thiol-ene polymers, Macromolecules, 1997, 30(23), 7322-7328.

29 S. M. Lai and G. L. Guo, Two-way shape memory effects of sulfur vulcanized natural rubber (NR) and NR/paraffin wax (PW)/carbon nanotube (CNT) nanocomposites, Polym. Test., 2019, 77, 105892.

30 S. Pattisson, E. Nowicka, U. N. Gupta, G. Shaw, R. L. Jenkins, D. J. Morgan and G. J. Hutchings, Tuning graphitic oxide for initiator-and metal-free aerobic epoxidation of linear alkenes, Nat. Commun., 2016, 7(1), 1-9.

31 S. Meenakshisundaram, M. Gopalakrishnan, S. Nagarajan, N. Sarathi and P. Sumathi, Kinetics and mechanism of the oxidation of alkenes by chromium (VI) in the presence of complexing agents, J. Chem. Res., 2005, 2005(2), 73-79.

$32 \mathrm{H}$. J. C. Boehm, Some aspects of the surface chemistry of carbon blacks and other carbons, Carbon, 1994, 32(5), 759769.

33 A. Contescu, Surface acidity of carbons characterized by their continuous pK distribution and Boehm titration, Carbon, 1997, 35(1), 83-94. 